\title{
Estágios iniciais de crescimento da pescada (Plagioscion monti Soares)
}

\author{
Heino Otto Walter Worthmann*
}

\begin{abstract}
Resumo
A idade de 370 especimes de P. monti foi determinada contando os anéis diários presentes nos otólitos. O comprimento padrăo dos peixes examinados varia de $0,7-15 \mathrm{~cm}$. Dentro deste intervalo de tamanho o aumento de comprimento pode ser considerado linear enquanto o aumento de peso uma função exponencial. A função para o aumento de comprimento foi: $L=0,0707 \mathrm{~T}+0,1263$; e para o peso $\mathrm{W}=4,86$ $10-5 T 2,5552$. O crescimento não é contínuo mas periodicamente interrompido em relação às fases da lua. 0 comportamento de desova também parece estar influenciado pela lua.
\end{abstract}

\section{INTRODUÇÃo}

A pescada é um peixe de grande importância comercial na bacia Amazônica com mais ou menos $300^{\circ} \mathrm{T} /$ ano vendidos em Manaus. Há várias espécies de pescada na região Solimões e Negro Amazonas, sendo as mais comuns Plagioscion squamosissimus e Plagioscion monti uma espécie nova descrita recentemente por Soares (1978).

Entretanto, nada se sabe, até agora, sobre a biologia e crescimento em condições naturais dessas espécies na região Amazônica. Foram realizados estudos de alimentação de $P$. squamosissimus na lagoa de Nazaré, Piauí por Silva \& Menezes (1950) e estudos de crescimento em cativeiros por Peixoto (1953) e Nomura (1976) .

$\mathrm{O}$ crescimento pode ser medido e analisado de várias maneiras. As experiências em aquário são difíceis de controlar, pois as condiçōes ecológicas naturais, como densidade de estoque, oferta de alimento, os quais influenciam o crescimento, não podem ser reproduzidas adequadamente. A coleta regular de amostras proporciona informações sobre crescimento só para aqueles peixes que exibem um crescimento rápido e, mesmo assim. só até um certo tamanho. O método "Petersen", distribuição de freqüência de tamanho, só pode ser aplicado, também, para peixes de rápido crescimento até 3-4 anos de idade. Experiências de marcação são efetivas só se um número grande de peixes for marcado e solto em uma área de intensa atividade pesqueira, garantindo assim um número razoáve! de recapturas. Além disso, a própria marca poderia influenciar o processo de crescimento. $\mathrm{O}$ método comumente usado, o de contagem de anéis sazonais de escamas e otólitơs, não é eficiente em águas tropicais, onde a temperatura da água é quase constante, pois mesmo quando estruturas diferentes são reconhecidas nos otólitos, não são de fácil interpretação.

O desenvolvimento de um método exato de determinação de idade foi possível quando Panella (1971) mostrou que material orgânico e inorgânico são depositados nos otólitos em rítmo diário, o que leva a um preciso conhecimento do fenômeno de crescimento.

Baseando-se nas análises dos anéis diários o objetivo deste trabalho foi o estudo do crescimento de Plagioscion monti Soares (1978).

\section{MATERIAL E MÉtodos}

Foi feita uma amostragem total de 684 espécimes de $P$. monti, capturadas no lago Janauacá com uma arrastadeira de malha de $5 \mathrm{~mm}$, em 11 de outubro de 1978. O lago Janauacá é um lago de várzea e situa-se na margem direita do rio Solimões cerca de $65 \mathrm{~km}$ de Manaus.

Dada a grande quantidade, os peixes foram preservados em álcool a $70 \%$ e levados ao 'aboratório para estudo posterior. O comprimen to padrão foi medido com aproximação ao milímetro inferior, e o peso determinado com aproximação ao miligrama inferior em uma balança Mettler P1200. Alterações nos comprimentos e pesos devidos à preservação em álcool foram corrigidas medindo e pesando uma nova amostragem de $157 P$. monti antes e após 7 dias no álcool. As curvas de conver- 
são computadas (Fig. $2+3$ ), podem ser cơnsideradas como regressões lineares porque apresentam correlações excelentes.

As funções mostraram, para comprimento: $y=1,0207 x+0,0438, \quad r=0,999$ e para o peso :

$y=1,4311 x-0,00886 \quad r=0,997$.

Limites de confiança de $95 \%$ para os coeficientes de regressão foram $\pm 0,0099$ para $\circ$ comprimento, $=0,0230$ para o peso, respectivamente. A idade foi determinada usando dois otólitos diferentes, sagita e asteriscus. A sagita é o otólito mais apropriado para peixes a partir de $2,5 \mathrm{~cm}$ de comprimento padräo. O asteriscus, que é o menor otólito foi utilizado para peixes de 0,7 até $2,5 \mathrm{~cm}$ de comprimento padräo.

Após cuidadosa extração do otólito, monta-se uma lâmina com Bálsamo de Canadá e faz-se, imediatamente, a leitura em microscópio binocular com aumento de $1000 \mathrm{x}$. Após 24 horas os asteriscus em Bálsamo apresenta-se demasiadamente transparente para que os anéis sejam reconhecíveis. Foram examinados 157 asteriscus para determinar a idade.

Em peixes de mais de $2,5 \mathrm{~cm}$ de comprimento padräo, o asteriscus é opaco demais para permitir uma leitura precisa dos anéis diários, portanto as sagitas foram utilizadas na determinação de idade em pescada maior que $2,5 \mathrm{~cm}$ de comprimento. Após a extração, as sagitas foram embutidas em "polyesther" e serradas em corte longitudinal mediano, por meio de uma serra especial. A lâmina cortada foi fixada, polida, imersa em ácido hidroclorídrico e montada em lâmina com Bálsamo de Canadá, sendo os anéis contados em um aumento de $1000 \mathrm{x}$.

Espécimes de $P$. monti até um comprimento padrão de $50 \mathrm{~mm}$, foram divididos em grupos de intervalos de $1 \mathrm{~mm}$. De cada grupo, foram retirados para exame 10 otólitos, quando possivel. Os espécimes apresentando um comprimento padrão maior que $50 \mathrm{~mm}$ foram divididos em grupos de intervalos de $1 \mathrm{~cm}$ e também de cada grupo 10 otólitos foram examinados. Um total de 370 otólitos foram examinados; 210 deses ótólitos foram da captura de 11 de outubro de 1978 , e 160 foram coletados no lago Janauacá durante 1978.

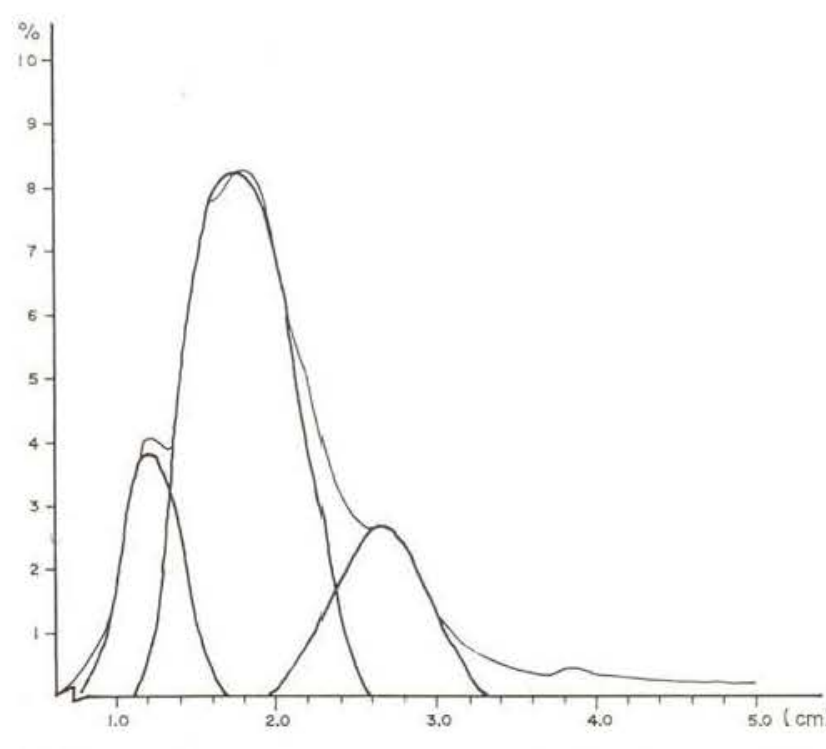

Fig. 1 - Distribuição de freqüência do tamanho de iuvenis P. monti capturadas no lago Janauacá em 11 de outubro de 1978, mostrado três periodos de desova.

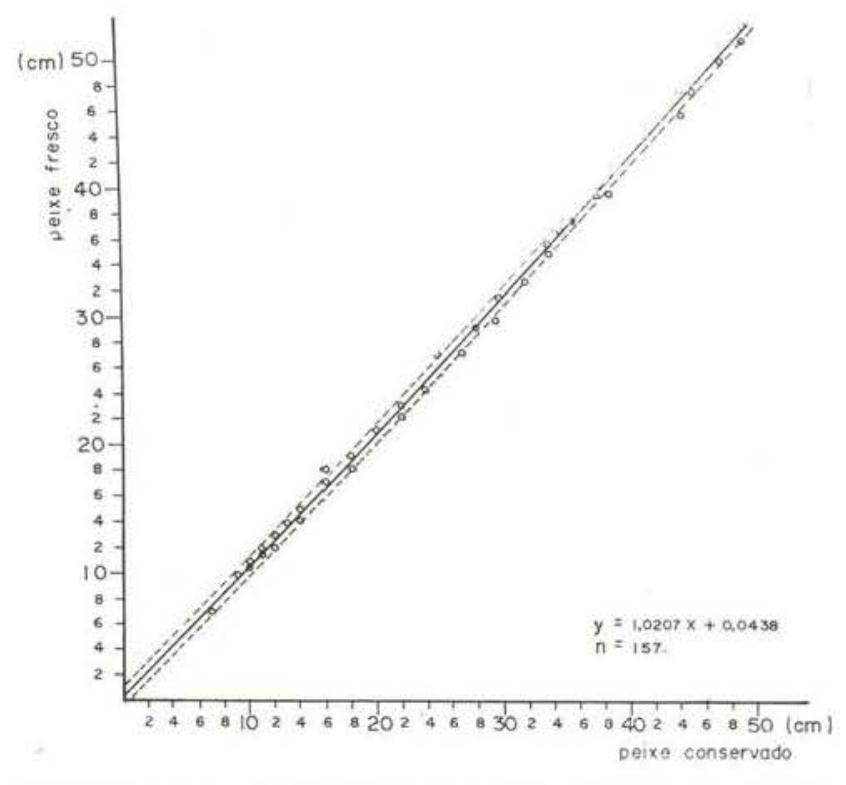

Fig. 2 - Recalculação do comprimento de P. monti conservadas e frescas. Linhas tracejadas indicam os limites de confiança de $95 \%$.

\section{RESUltados E Discussão}

Informações sobre a formação e desenvolvimento simultâneo dos três otólitos (asteriscus, lapillos e sagitta) não foram encontrados na literatura. O desenvolvimento irreguiar entre os três otólitos invalidaria o uso de diferentes otólitos na determinação de idade em 


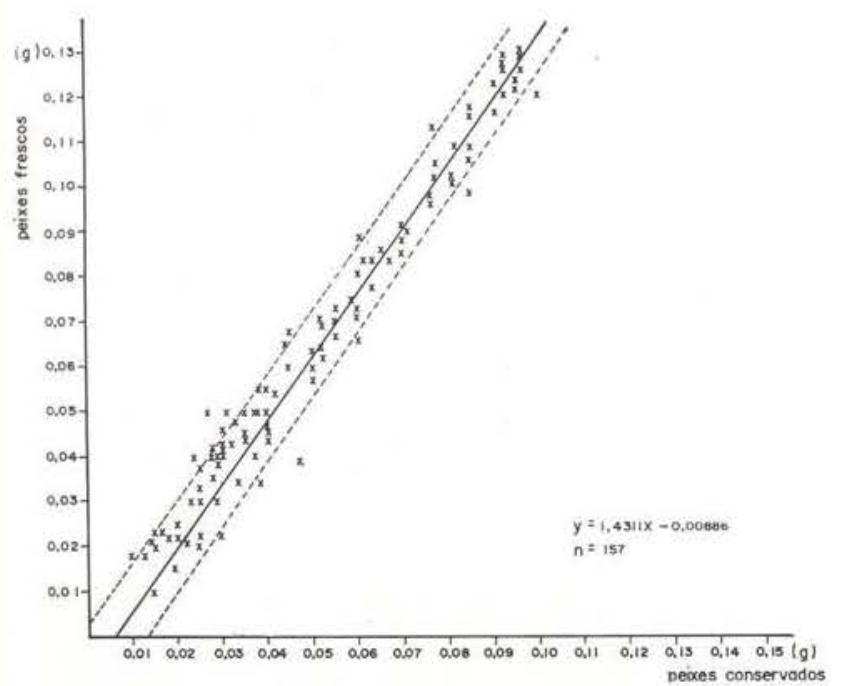

Fig. 3 - Recalculação do peso de P. monti conservadas e frescas. Linhas tracejadas indicam os limites da confiança de $95 \%$.

peixes. Fisiologicamente, seria razoável espera: que o asteriscus, lapillus e sagitta, desenvolvessem ao mesmo tempo.

Mugiya (1967) achou uma correlação entre a composição química do "endolinfa" e a disposição das zonas hialinas e opacas na sagitta. Como os três otólitos se comunicam com os arcos do órgão labiríntico, a origem simultânéa dos otólitos é de se esperar. Os otólitos responsáveis pelo equilíbrio em peixes, desenvolvem funçōes diferentes, lapillos em acele. ração e gravidade, saggitta principalmente com audição, e asteriscus com mudanças posicionais. Portanto, é difícil imaginar a razão pela qual um dos sentidos seria favorecido pelo desenvolvimento prematuro de um dos otólitos. Visando este problema, os três diferentes otólitos de cinco espécimes de $P$. monti, de $1,2 \mathrm{~cm}$ de comprimento foram examinados para comparar o número de anéis diários. Os asteríscus foram embutidos em Euparal e lidos imediatamente. As sagittas e lapillos foram primeiramente clarificadas em xilol por três dias e após, embutidas em Euparal e lidos. Em todos os casos, um número igual de anéis diários foram encontrados, indicando que os otólitos são formados ao mesmo tempc.

A identificação e contagem dos padrões diários nos otólitos provou ser mais difícil do que se esperava, dada a presença de anéis secundários de origem desconhecida. Nos asteriscus, apenas anéis que mostravam no mínimo $80 \%$ de uma faixa em torno do centro, foram contados.

$\mathrm{Na}$ região dos sulcos acústicus, os anéis diários, às vezes, se unem pois esta é a área de crescimento vagaroso. Porém, os anéis diários das sagittas só podem ser lidos ao redor dos sulcus acústicus. Aqui os anéis foram reiativamente fáceis de reconhecer como faixas periódicas (Fig. 4). Na região imediata dos sulcos acústicus, porém, as faixas se unem transformando-se em intervalos de tempo não identificáveis.

Worthmann (1979) mostrou que o crescimento do otólito da pescada está correlacionado com o crescimento do peixe. O crescimen. to em sentido longitudinal, porém é maior que o crescimento da largura e espessura. Portan-

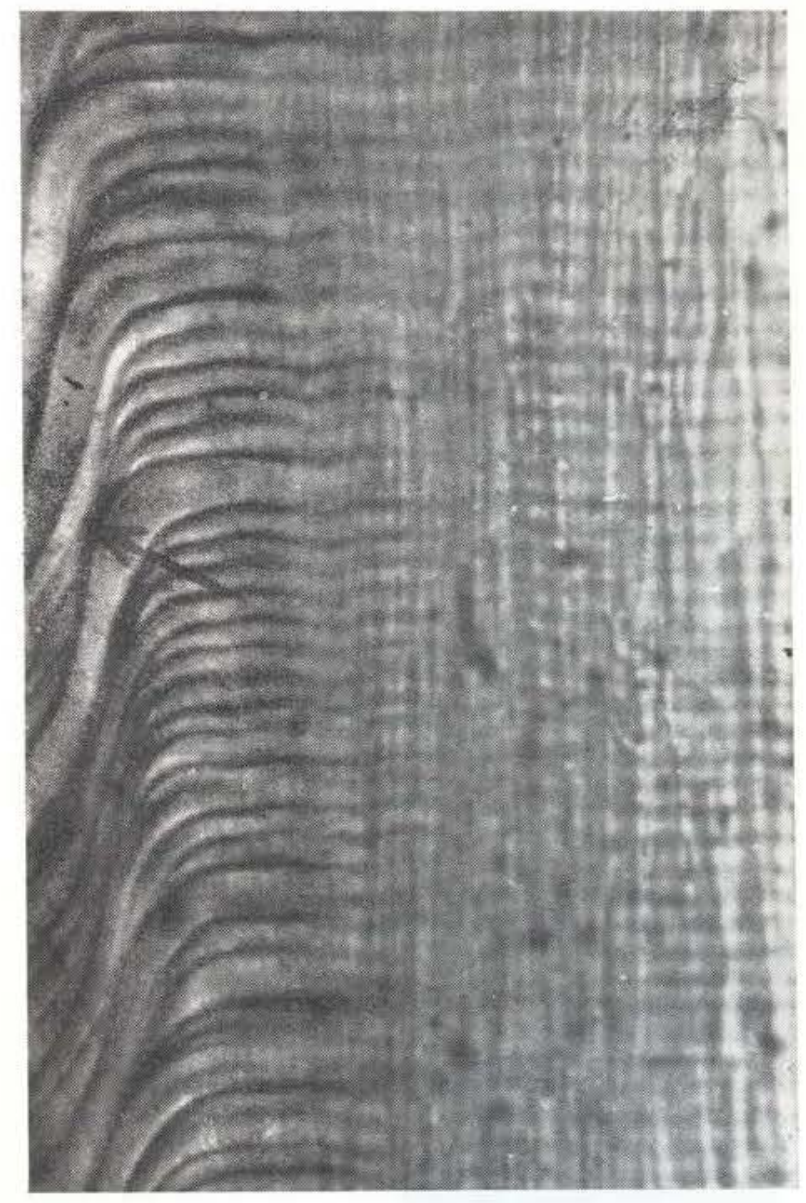

Fig. 4 - Camadas diárias de uma sagitta de P. monti conjugando-se na área do sulcus acusticus (seta). Amplificação 1000x. 


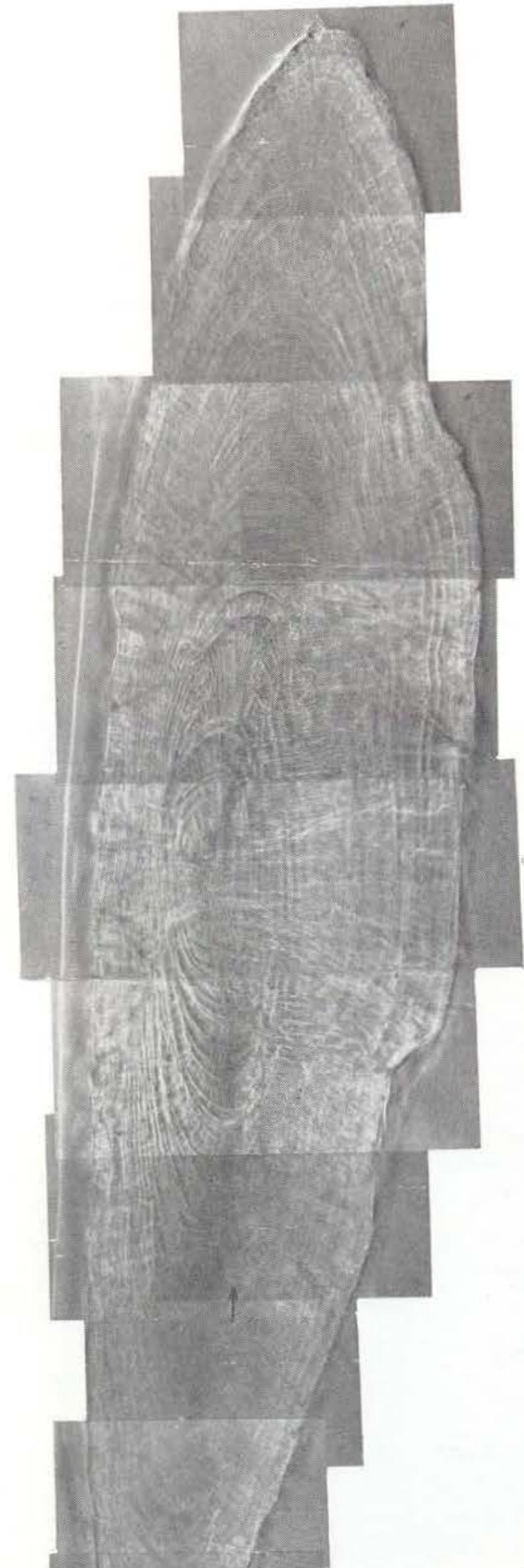

to, interrupções irregulares na área do eixo longitudinal ocorre fazendo com que a determinação de idade seja impossível. (Fig. 5) . Também foi difícil cortar e lixar as sagittas. porque no caso de não estar centralizado exatamente, os primeiros anéis se perdiam. A fig. 6 mostra os primeiros anéis diários de urna sagitta.

$\mathrm{Na}$ tabela 1, a idade de grupos de intervalos de $\mathrm{cm}$ está resumida em classes de 10 dias, porque em peixes com mais de $2,5 \mathrm{~cm}$ de comprimento a determinação precisa não foi

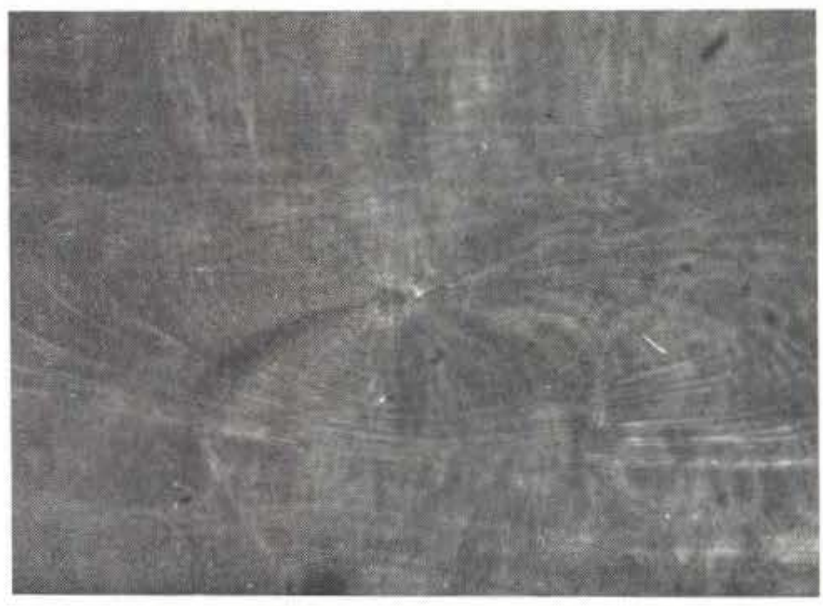

Fig. 6-Centro de uma sagitta de P. monti, mostrando os primeiros anéis diários. Amplificação 1000x.

possivel, face ao centro dos otólitos, em muitos casos, năo ser encontrado. $O$ crescimentc em comprimento e peso foi expressa por $\mathrm{V}$. Bertalanffy (1934) pelas equações :

$$
\begin{aligned}
& \mathrm{L}_{\mathrm{t}}=\mathrm{L}_{\infty}\left[1-\mathrm{e}^{-\mathrm{k}(\mathrm{t}-\mathrm{t})} \mathrm{o}\right] \\
& \mathrm{W}_{\mathrm{t}}=\mathrm{W}_{\infty}\left[1-\mathrm{e}^{-\mathrm{k}(\mathrm{t}-\mathrm{t})}\right]^{3}
\end{aligned}
$$$$
W \cong L^{3}
$$

O crescimento do comprimento aproximase assintoticamente num valor $L_{\infty}$ depois de

Fig. 5 - Sagitta de um P. monti de $1,7 \mathrm{~cm}$ comprimento padrão mostrando interrupçōes no eixo longitudinal (seta) Amplificaçāo 400x. 
um progresso inicial crescente bem acentuado que depende da constante $\mathrm{K}$ do crescimento. O aumento do peso está representado como uma curva sigmóide com o valor final assintótico $\mathrm{W}_{\infty}$.

Para um período curto da vida, menos de um ano (Tab. 1), o crescimento do comprimento pode ser expresso como uma regressão linear $Y=a x+b$, e a curva de peso como uma funçăo exponencial $\mathrm{Y}=a x^{b}$. função :

O crescimento está representado pela

$$
\begin{aligned}
& \mathrm{L}=0,0707 \mathrm{~T}+0,1263 \text { e o Peso : } \\
& \mathrm{W}-4,86 \cdot 10 \mathrm{~T} \mathrm{~T}^{2,5552} \mathrm{~T}=\text { idade em dias. }
\end{aligned}
$$

Para as duas funções, os dados foram bem correlacionados. Para a relação de comprimento com o tempo, um fator de correlação de $r=0,99$ foi calculado e para o peso com tempo, $r=0,97$. O intervalo da confiança de $95 \%$ para o coficiente da regressão do comprimento foi $\pm 0,0016$. O valor dos limites da confiança para o peso foi $\pm 0,0846$. P. monti cresce mais lentamente em condições naturais do que $P$. squamosissimus criada em condições artificiais por Peixoto (1953). Um aumento em comprimento de $1,15 \mathrm{~mm}$ por dia foi encontrado em $P$. squamosissimus, enquanto que um aumento de $0,7 \mathrm{~mm}$ foi observado em $P$. monti.

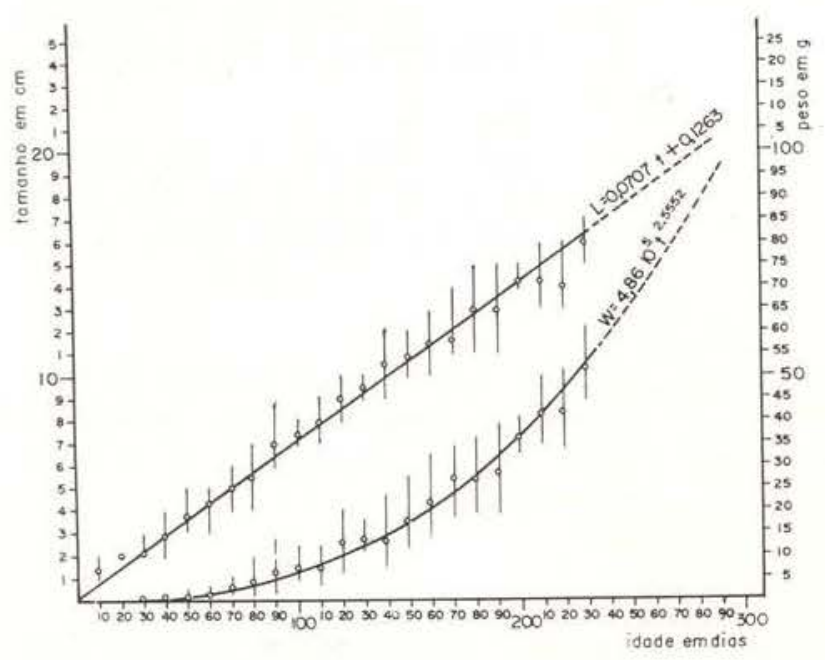

Fig. 7 - Curvas do crescimento do comprimento e peso de P. monti.
Dado o aumento de peso não ser uma constante linear, incrementos de aumento não podem ser dados diariamente, mas sim em maiores intervalos de tempo. Peixoto (1953) notou em $P$. squamosissimus um aumento no peso médio diário de $0,108 \mathrm{~g}$ para exemplares entre $28-86 \mathrm{~mm}$ de comprimento. Neste intervalo de comprimento, o aumento no peso médio diário de $P$. monti mostrou ser de $0,12 \mathrm{~g}$.

Para exemplares entre $86-120 \mathrm{~mm}$ de comprimento de $P$. squamosissimus, Peixoto (1953) calculou um aumento médio diário no peso de $0,386 \mathrm{~g}$ enquanto que nós observamos um aumento diário no peso de $0,25 \mathrm{~g}$ em $P$. monti, embora $P$. monti tenha no início do crescimento um aumento de peso mais rápido, $P$. squamosissimus, de uma maneira geral, mos. tra um aumento de peso mais acelerado. Estudos preliminares de $P$. squamosissimus, em condições naturais no lago Janauacá também sugere isto.

Quando comprimento é plotado contra intervalos de tempos curtos de um dia, pode ser observado que não há uma taxa constante de crescimento mas, sim uma taxa que é inter. rompida em intervalos regulares que ocorrem de $12-14$ dias de acordo com as fases da lua. (Fig. 8). A taxa de crescimento é reduzida durante períodos de lua nova e cheia, embora ainda não se tenha explicação para este fenô meno. Da amostra de 11 de outubro de 1978 , a contagem dos anéis de crescimento demonstrou interrupções coincidentes com as fases da lua: a primeira interrupção entre 5-7 de setembro, 35 - 37 dias antes da captura, com uma fase de lua nova por volta de 2 de setembro de 1978; a segunda interrupção ocorreu entre 1618 de setembro quando houve lua cheia no dia 16 do mesmo; a terceira apareceu em 29 de setembro com lua nova ocorrendo no dia 2 de outubro. A influência das fases da lua em crescimento já foi observado em alguns animais marinhos, incluindo peixes. Panella (1971) observou estruturas de anéis mensais e quinzenais recorrentes em várias espécies de peixes. Bingel (1972) menciona faixas de crescimento mensais e semi-mensais nos otólitos de bacalhau. Também se sabe que a lua atinge o comportamento de desova de peixes principalmente por causa da influência das 


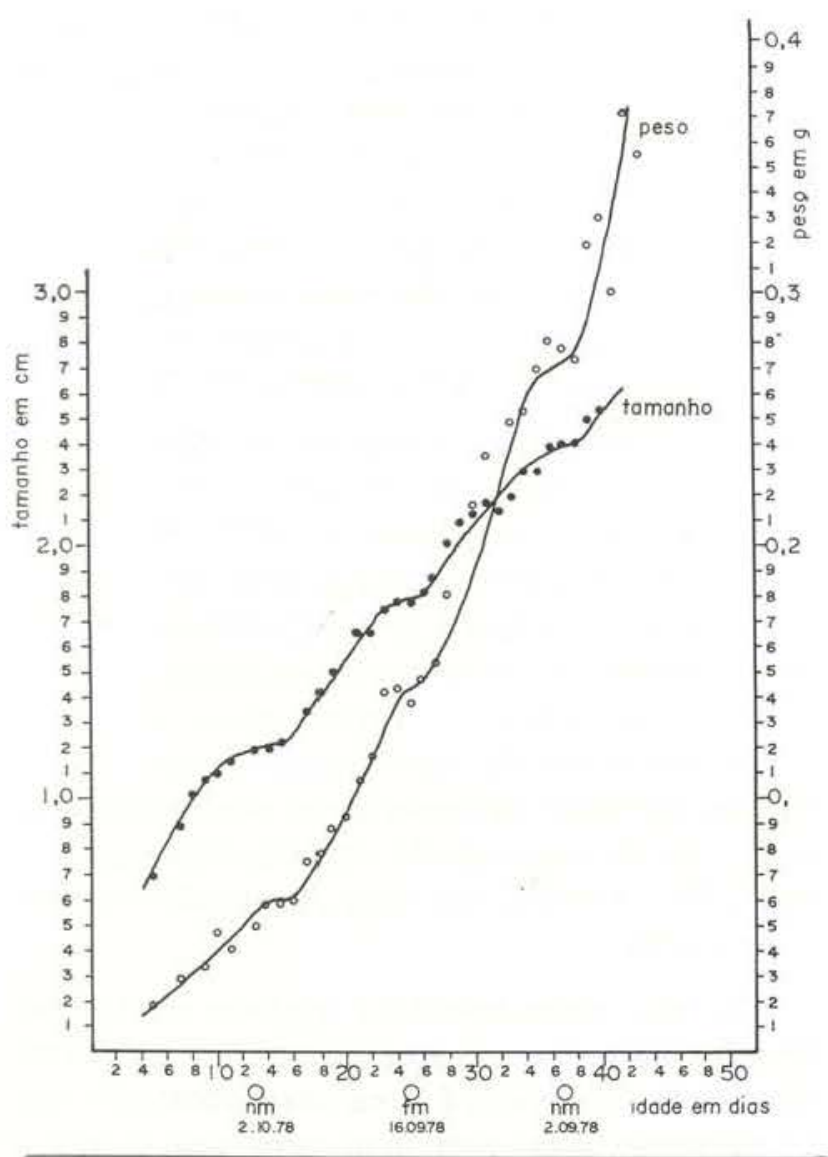

Fig. 8-Curvas do crescimento do comprimento e peso de P. monti em intervalos diários, mostrando interrupções nas fases da lua nova (In) e lua cheia (Ic).

marés. Kennedy \& Pearse (1975) sugerem que não são as marés responsáveis pelo comportamento de desova de ouriço do mar (Centrostephanus coronatos), mas sim as mudanças mensais na intesidade da luz lunar. Para águas interiores que não dependem de marés as mudanças na intensidade de luz lunar pode ser um fator decisivo no comportametno de desova de muitos peixes. Um rítmo de desova depenclente da lua pode ser um fenômeno que ocorre $\operatorname{com} P$. monti. Na Fig. 1 a distribuição de freqüência de tamanho dos peixes jovens capturados no Janauacá pode ser dividido em grupos de acordo com o método de Cassie (1957). Cada um destes grupos significa um período de desova. Os três picos da distribuição encontram-se a $1,2 \mathrm{~cm}, 1,8 \mathrm{~cm}$ e $2,7 \mathrm{~cm}$ respectivamente. Se estes dados são transferido à curva de crescimento (Fig. 8) corresponderão aos períodos aonde há interrupções no crescimento. Só o último grupo não mostra uma correlação exata, mas isto pode ser devido às maiores variações no comprimento por idade que ocorrem neste grupo. $P$. monti mostra um comportamento de desova dependente da lua, desovando em época de lua cheia e de lua nova.

\section{SUMMARY}

The age of 370 specimens of P. monti was determined by means of daily rings on the otoliths. The length of the fish were in the range of $0,7-15 \mathrm{~cm}$. Within this size interval, the increase in length can be assumed to be linear, and the increase in weight to be an exponential function. The function for increase in length was $L=0,0707 T+0,1263$ and for weight $W=4,8610-5 T 2,5552$. Growth is not continuous, but interrupted periodically in relation to the phases of the moon. Spawning behaviour also appears to be influenced by the moon.

\section{BIBLIOGRAFIA}

BERTALANFFY, L.V.

1934 - Untersuchungen über die Gesetzlichkeit Wachstumes. I. Allgemeine Grundiage der Theorie. Arch. Entw Mech. Org., 131 613-652.

BINGEL, $\mathrm{F}$.
1972 - Zur Interpretation con Otolithenstrukturen des Dorsches (Gadus morthua L.) - Diplomarbeit Kiel $39 \mathrm{p}$.

CASSIE, R.M.

1954 - Some uses of propability paper in the analises of size frequency distributions. Aust. J. mar. Freshwater Res., $5:$ 513-522.

Kennedy, B. \& Pearse, J.S.

1975 - Lunar synchronization of the monthly reproductive rhythm in the sea urchin Centrostephanus coronatus Verril. J. Exp. Mar. Biol, Ecol., 17(3) : 223-331.

Nomura, $\mathrm{H}$.

1976 - Idade e crescimento da Pescada do Piauí, Plagioscion squamosissimus Heckel, do açude Amanari (Mananguape, Ceará), Revista Ceres, 23(127) : 191-197.

MUGIYA, Y.

1964 - Calcification in fish and shell-fish. III. Seasonal occurrence of a prealbumin fraction in the otolith fluid of some fish, corresponding to the period of opaque zone formation in the otolith. Bull. of the Jap. Soc. of Sci. Fish., 30(2) : 955-961. 
PANella, G.

1971 - Fish otoliths: Daily growth layers and periodical patterns. Science. 137 (4002).

PeIXoto, J.T

1953 - Contribuição para o estudo do crescimento da corvina Plagioscion squamosissimus (Heckel 1840) em cativeiro. Rev. Brasil. Biol., 13(2) : 173-177.

Silva, S.L. \& Menezes, R.S.

1950 - Alimentação de Corvina, Plagioscion squamosissimus (Heckel 1840). Rev. Bras. Biol.. $10(2): 257-264$.
SOARES, L.

1978 - Revisão taxonômica dos scianideos de água doce da regiăo Amazônica Brasileira. Manaus. Tese de mestrado.

WORTHMANN, H.O

$$
\begin{aligned}
& 1979 \text { - A relação entre o desenvolvimento do } \\
& \text { otólito e o crescimento do peixe como } \\
& \text { auxilio na distribuiçāo de populaçōes de } \\
& \text { Pescada (Plagioscion squamosissimus). } \\
& \text { Acta Amazônica, } 9(3): 573-86 \text {. }
\end{aligned}
$$

(Aceito para publicação em 12/11/79) 
TABELA 1 - Idade de P. monti em dias por $\mathbf{c m}$ de comprimento

\begin{tabular}{|c|c|c|c|c|c|c|c|c|c|c|c|c|c|c|c|c|c|c|c|c|c|c|c|c|c|c|}
\hline $\begin{array}{c}\text { comprimento } \\
\text { em cm }\end{array}$ & ${ }_{10}^{0-}$ & $\begin{array}{c}11- \\
20\end{array}$ & $\begin{array}{c}21- \\
30\end{array}$ & $\begin{array}{c}31- \\
40\end{array}$ & $\begin{array}{c}41- \\
50\end{array}$ & $\begin{array}{c}51- \\
60\end{array}$ & $\begin{array}{c}61- \\
70\end{array}$ & $\begin{array}{c}71- \\
80\end{array}$ & $\begin{array}{c}81- \\
90\end{array}$ & $\begin{array}{l}91- \\
100\end{array}$ & $\begin{array}{c}101- \\
110\end{array}$ & $\begin{array}{c}111- \\
120\end{array}$ & $\begin{array}{c}121- \\
130\end{array}$ & $\begin{array}{c}131- \\
140\end{array}$ & $\begin{array}{c}141- \\
150\end{array}$ & $\begin{array}{r}151- \\
160\end{array}$ & $\begin{array}{r}161- \\
170\end{array}$ & $\begin{array}{c}171- \\
180\end{array}$ & $\begin{array}{c}181- \\
190\end{array}$ & $\begin{array}{l}191- \\
200\end{array}$ & $\begin{array}{c}201- \\
210\end{array}$ & $\begin{array}{c}211- \\
220\end{array}$ & $\begin{array}{l}221- \\
230\end{array}$ & $\begin{array}{c}231- \\
240\end{array}$ & $\begin{array}{r}241- \\
250\end{array}$ & $\Sigma$ \\
\hline 1 & 8 & & & & & & & & & & & & & & & & & & & & & & & & & 8 \\
\hline 2 & 6 & 44 & 42 & 3 & & & & & & & & & & & & & & & & & & & & & & 95 \\
\hline 3 & & & 7 & 33 & 12 & 2 & & & & & & & & & & & & & & & & & & & & 54 \\
\hline 4 & & & & 2 & 26 & 16 & 8 & & & & & & & & & & & & & & & & & & . & 53 \\
\hline 5 & & & & & 5 & 17 & 23 & & & & & & & & & & & & & & & & & & & 53 \\
\hline 6 & & & & & & & 11 & 7 & 2 & & & & & - & & & & & & & & & & & & 20 \\
\hline 7 & & & & & & & & 1 & 2 & 5 & 1 & & & & & & & & & & & & & & & 9 \\
\hline 8 & & & & & & & & & 2 & 3 & 2 & 2 & & & & & & & & & & & & & & 9 \\
\hline 9 & & & & & & & & & & & 1 & 4 & 4 & 1 & & & & & & & & & & & & 10 \\
\hline 10 & & & & & & & & & & & & 2 & 6 & & 1 & 1 & & & & & & & & & & 10 \\
\hline 11 & & & & & & & & & & & & & & 1 & 1 & 2 & 4 & 1 & 1 & & & & & & & 10 \\
\hline 12 & & & & & & & & & & & & & & 1 & 1 & 2 & 2 & 1 & 2 & & & & & & & 9 \\
\hline 13 & & & & & & & & & & & & & & & & 1 & & 3 & 3 & & 1 & 1 & & & & 9 \\
\hline 14 & & & & & & & & & & & & & & & & & 1 & 1 & 2 & 5 & 1 & 2 & 1 & & & 13 \\
\hline 15 & & & & & & & & & & & & & & & & & & 1 & 1 & 1 & 2 & 1 & 1 & & 1 & 8 \\
\hline$\Sigma$ & 14 & 44 & 49 & 38 & 43 & 35 & 42 & 17 & 6 & 8 & 4 & 8 & 10 & 3 & 3 & 6 & 7 & 7 & 9 & 6 & 4 & 4 & 2 & & 1 & 370 \\
\hline
\end{tabular}

